\title{
CORPUS Corpus
}

Archivos virtuales de la alteridad americana

Vol 4, No $1 \mid 2014$

Enero / Junio 2014

\section{"Fuentes indígenas" en la Sudamérica colonial y republicana: escritura, poder y memoria. Parte 2}

Guillermo Wilde

\section{OpenEdition}

Journals

Edición electrónica

URL: http://journals.openedition.org/corpusarchivos/641

DOI: 10.4000/corpusarchivos.641

ISSN: 1853-8037

Editor

Diego Escolar

Referencia electrónica

Guillermo Wilde, «"Fuentes indígenas" en la Sudamérica colonial y republicana: escritura, poder y memoria. Parte 2 », Corpus [En línea], Vol 4, No $1 \mid$ 2014, Publicado el 30 junio 2014, consultado el 04 mayo 2019. URL : http://journals.openedition.org/corpusarchivos/641; DOI : 10.4000/ corpusarchivos.641

Este documento fue generado automáticamente el 4 mayo 2019.

Licencia Creative Commons: Atribución-NoComercial 2.5 Argentina (CC BY-NC 2.5 AR) 


\title{
"Fuentes indígenas" en la Sudamérica colonial y republicana: escritura, poder y memoria. Parte 2
}

\author{
Guillermo Wilde
}

\section{NOTA DEL EDITOR}

Fecha de recepción del original: 10/03/2014

Fecha de aceptación para publicación: 28/04/2014

\section{Introducción}

1 La discusión sobre las "fuentes indígenas" interroga tanto la problemática de la agencia indígena inscripta en la producción textual, lo que conlleva pensar sobre las apropiaciones que los indígenas hacen de las tecnologías y los saberes no indígenas, como los dispositivos que ponen en juego las instituciones y agentes coloniales para gobernar el territorio y la población, dando contornos a los actores indígenas en sus operaciones discursivas, sea para acentuar sus condicionamientos o para establecer el alcance de sus derechos. De esta doble interrogación deriva una antropología histórica interesada en dar cuenta de la historia de "los que no tenían voz" y, simultáneamente, por "emprender una crítica de los procedimientos de nominación, denominación y de representación del pasado"; un interés por la "agentividad de los subalternos" y una crítica de las categorías por medio de las cuales el discurso hegemónico clasificó, normalizó e invisibilizó a los grupos indígenas (Boccara, 2012, pp. 41, 43-44).

2 ¿Cuáles son los temas y códigos predominantes en las narrativas sobre la alteridad? ¿Constituyen acaso los textos coloniales hegemónicos formas seminales de descripción 
etnográfica? ¿Qué tipo de separaciones y antinomias producen y en qué se asemejan a las clasificaciones que los mismos nativos producen?

Estas preguntas nos llevan a una primera cuestión para el debate, relacionada con los modos de producción de conocimiento sobre el Nuevo Mundo. Aún no contamos con una tipología lo suficientemente sistemática y exhaustiva de los diferentes géneros documentales producidos entre el siglo XVI y el siglo XIX para referir a las poblaciones locales. Entre los factores que modulan esos géneros, sin duda debe tenerse en cuenta la dimensión espacial. Aldeias, reducciones, ciudades, vilas, presidios, estancias, entre muchos otros espacios, manifiestan la diversidad de la presencia (o la existencia) indígena en el marco colonial y republicano, lo que tiene consecuencias directas en la conformación de un corpus de textos; los condicionamientos mayores o menores que imponen esos espacios resultan cruciales al identificar "voces indígenas" en un momento determinado, al igual que rupturas y continuidades a lo largo del tiempo.

4 La consideración global del corpus exige también distinguir estilos y niveles de articulación discursiva muy diferentes, desde los modelos generales y abstractos de conocimiento impulsados por el aparato colonial, hasta las narrativas del contacto que incluyen anécdotas personales y diálogos inspirados en las interacciones cotidianas. Parece una obsesión del primer tipo de texto la introducción de clasificaciones que se cristalizan en la época, y en muchos casos tienen vigencia hasta bien entrado el siglo XIX, cuando los estados independientes heredan el legado nominador vigente durante la época colonial tardía. Tupi-Tapuia, aliado-enemigo, povoado-sertao, poblado-despoblado, civilidad-gentilidad, son algunas de esas dicotomías destinadas a organizar la fronteras materiales y simbólicas del Nuevo Mundo (Herzog, 2007). Si bien expresan proyecciones de las sociedades europeas productoras sobre un universo desconocido, también condicionan modos de acercamiento y alianza con la población nativa. Este postulado no está exento de simplificaciones, pues, ¿cuánto pesan las diferentes tradiciones nacionales (y regionales) europeas de los productores de textos (española, portuguesa, inglesa, holandesa, francesa) en la gestación de narrativas y representaciones diferenciadas? Se trata de una pregunta que no ha recibido una respuesta satisfactoria hasta el momento ${ }^{1}$ La conexión entre la escala del imperio y las voces de sus agentes locales aún debe ser sometida a un análisis en profundidad, especialmente en las regiones que escapan a un control rígido de las instituciones metropolitanas.

5 La segunda parte de este dossier refiere precisamente a esas regiones que, grosso modo, podríamos llamar "fronterizas". Incluye documentos referentes al Paraguay colonial temprano, al Chile austral, al Chaco, la región de Chiquitos y las reducciones guaraníes. Las discusiones que colocan los autores remiten al menos a tres temas planteados por este dossier, que continúan con las reflexiones de la primera parte publicada en el vol. 3 no 1 de revista Corpus. En primer lugar, la problemática de las clasificaciones étnicas y políticas. En segundo lugar, la capacidad de representación de la población indígena por parte de ciertos documentos, especialmente los producidos por misioneros. En tercer lugar, las modulaciones de estilo, narrativa y lenguaje ocasionadas con la transición de la Colonia a la etapa independiente. Sin pretender ser exhaustivo, en esta introducción propongo una breve discusión de cada uno de esos temas a partir del contenido de las seis contribuciones nuevas. 


\section{De las clasificaciones coloniales a las voces indígenas, $\mathrm{y}$ viceversa}

6 La primera contribución, de Guillaume Candela, incluye tres llamativos documentos de la época temprana de la conquista del Paraguay, una zona periférica sobre la que la historiografía asumía que ya no había mucho por decir debido a "falta de fuentes". Los hallazgos documentales recientes de Candela vuelven a colocar en el centro de la discusión las características de la participación indígena en la época de los primeros contactos y exploraciones. Como muestran los documentos, los conquistadores clasificaban a esta población recurriendo a una enorme cantidad de denominaciones étnicas ${ }^{2}$. Los documentos transcritos por Candela hacen referencias a "guaxarapos", "gacamos", “turubones", “ayguas", “chanes", “taycocis", "rucocis", "guaracocis", "xarayes", "payaguas", "carios" y "tupis", muchos de los cuales desaparecen de las fuentes oficiales en las décadas posteriores.

7 Los conquistadores también apelaban a los conocimientos indígenas obtenidos en las interacciones para alimentar sus propias cosmovisiones utópicas sobre tierras de riqueza y el supuesto paso antiguo de cristianos por la región (Stern, 1992) ${ }^{3}$. La región se encontraba prácticamente inexplorada en la época, y sobre ella existía la duda sobre la existencia de antiguos caminos supuestamente recorridos por otros cristianos, antes de la llegada de los conquistadores. Se pregunta a los indios si "antes de ahora han visto o oído decir de cristianos". Y los indios responden afirmativamente, que hacía mucho tiempo había pasado un cristiano llamado Maratia, que hablaba guaraní, con muchos indios, pero que no había vuelto por allí. Y agregaban los indios interrogados que "muchos cristianos habían entrado por la tierra adentro a los Paycunos y que trayendo mucho metal los habían muertos los Payaguaes los cuales trayendo todo el".

8 La siguiente contribución, de Hugo Contreras Cruces, nos introduce en un contexto diferente, el Chile colonial, donde a partir de una serie de documentaciones administrativas especialmente seleccionadas, descubrimos los problemas cotidianos de la interacción social y cultural de la frontera austral. Aunque Contreras Cruces reconoce que esta documentación "desde el punto de vista de su producción" difícilmente pueda ser considerada parte de un corpus de "fuentes indígenas", no niega ni la gran cantidad ni la trascendencia de la información que entregan,

(...) pues si bien en ellas está presente centralmente la representación que hacen sus productores de los indios y, en tal sentido, permiten construir una imagen de los mismos guiada por sus palabras, esta no es la única alternativa al momento de emprender su análisis.

Problema parecido plantea en otra contribución del dossier Francismar Alex Lopes de Carvalho, a propósito de informes de funcionarios en la región de Chiquitos. Contrera Cruces incluye descripciones de hechos "tanto generales como específicos" redactados después de ocurridos con el objetivo de dictar normativa destinada a subsanar los problemas detectados. Prolifera en estos documentos el uso de términos como "borrachera", "hambi", "cuzcos", "aucas" que refieren a las prácticas que se busca controlar o a los orígenes étnicos de sus practicantes. Las fuentes también revelan el involucramiento que la sociedad criolla tiene en las prácticas condenadas por la administración en una región alejada de los controles centrales y altamente condicionada por la escasez económica. 
10 A continuación María Laura Salinas y Pedro Omar Svriz Wucherer presentan documentos de interés para el estudio de la dinámica de los pueblos de indios en la región de Corrientes. A diferencia de sus vecinas, las reducciones jesuíticas del Paraguay tratadas por Neumann en la primera parte de este dossier y por Couchonnal y Wilde en esta, los pueblos en cuestión se encuentran sujetos a la institución de la encomienda, y muchos de sus reclamos y batallas tienen que ver con las condiciones que se les imponen en ese duro régimen, o con la conciencia clara que tienen de hacer valer sus derechos según la ley indiana.

11 Uno de los documentos transcritos es un fragmento de la importante visita del oidor Andrés Garabito de León. Otra es una carta de un cacique y corregidor. En ambos casos aparece como protagonista la familia Canindeyú. La fuente plantea reflexiones en torno del estatuto y derecho de la población indígena, pero también aspectos relacionados con la delimitación de la organización social indígena a partir del uso de términos como "parcialidad" o "cacicazgo", de donde se desprenden también disputas entre los mismos indígenas. Esta documentación permite acercarnos al liderazgo indígena como la manifestación de un middleground que conecta las formas nativas de construcción de prestigio y las normativas del régimen colonial.

En estas tres primeras contribuciones se presenta la cuestión de las clasificaciones en diferentes modalidades. Si los primeros conquistadores del Paraguay estaban interesados en identificar a estas poblaciones apelando a una diversidad de nombres étnicos, muchos de ellos seguramente de uso común entre los mismos indígenas, los administradores del Chile colonial también se inclinan por establecer clasificaciones étnicas, pero sobre todo morales, distinguiendo los comportamientos adecuados de los inadecuados para el mantenimiento del buen orden civil. En tanto que en el contexto correntino se introduce una preocupación por establecer una organización política estable basada en el reforzamiento del poder local y la figura canónica del "cacicazgo".

13 Salinas y Svriz Wucherer legítimamente plantean una discusión sobre las "fuentes referidas a indígenas", que "recogen voces de indígenas, al haber sido rescatadas, escritura mediante, por la estructura colonial (escribano o eventual escribiente)", lo que implica "leer entre líneas dichas intervenciones, estar atentos a todos los detalles y con buen criterio seleccionar los aspectos que pueden ser útiles a nuestras investigaciones". Y se interrogan

(...) hasta qué punto dichos escritos nos ponen en contacto con los actores a los que hacen referencia.Y sumamos la inquietud sobre si pierden valor por no haber sido producidas directamente por los protagonistas a los que se menciona. (...) en el caso de haber sido escritas por los mismos indígenas jofrecen una mayor confiabilidad por no haber mediado un amanuense? ¿Nos permiten acercarnos en mayor medida a su mundo?

14 Estas reflexiones nos conducen a la segunda cuestión que nos interesa tratar aquí, sobre la capacidad de las fuentes para representar la dinámica indígena y la naturaleza más o menos etnográfica que asociamos a algunos géneros documentales.

\section{Géneros misioneros, escritura etnográfica y adaptación cultural}

En la cuarta contribución al dossier, Beatriz Vitar se detiene en fragmentos de la Descripción corográfica del Gran Chaco Gualamba, del jesuita Pedro Lozano, referente a la 
pacificación de los indios "malbalaes" en el siglo XVIII. Llama la atención de Vitar el hecho de que la fuente incluya frases en primera persona atribuidas al cacique "principal" de la etnia, finalmente conquistada y pacificada.Como signo de paz, un líder malbalá había entregado al gobernador del Tucumán un mensaje enarbolado en el extremo de un dardo. Escribe Vitar:

Detrás de lo que a primera vista puede parecer una manipulación de la voluntad y de la palabra indígena -el acto de sujeción expresado a través de la escritura en español y con la retórica al uso- subyacía una trama urdida al calor de las relaciones interétnicas y de los condicionamientos derivados de la presión colonial, como lo demuestran los sucesos producidos antes y después de las capitulaciones.

Desde el inicio Vitar señala algunos comentarios metodológicos a propósito de la naturaleza de la fuente que conviene traer a la discusión. Uno de ellos sugiere que los textos que conforman el "monumental corpus de crónicas que construyeron la imagen de la alteridad (...) desde la posición privilegiada del lugar de enunciación asociado al poder imperial" fueron "también en cierta manera obra de los pueblos nativos, cuyas acciones, palabras y gestos narrados por los otros definen una agencia indígena en el marco de unas desiguales y conflictivas relaciones con el mundo colonial". En efecto, muchas veces las voces indígenas paradojalmente "hablan" a través de las fuentes producidas en el marco del aparato colonial.

Ya hemos prestado alguna atención a la definición de la "fuente indígena" como producto directo de los mismos actores indígenas ${ }^{4}$. Ahora bien, el documento en cuestión permite circunscribir otro aspecto importante del debate. ¿En qué medida un texto producido por un no indígena puede convertirse en una "fuente indígena", es decir, en una fuente capaz de representar la alteridad? ¿Es acaso eso posible, sin tener en cuenta las múltiples mediaciones en juego, y el hecho, tal vez ineludible, de que todo texto sobre la alteridad es,en algún punto, etnocéntrico (además de anacrónico, si refiere a una experiencia del pasado)?

El discurso de los agentes coloniales no indígenas, particularmente el de los misioneros, suele exhibir muchas modulaciones y fisuras, especialmente si resulta del contacto con la población indígena en las áreas fronterizas. Esto permite reconocer lo que hemos llamado "voces indígenas encapsuladas" dentro de los textos; un principio de multivocidad y polifonía, para utilizar el lenguaje posmoderno. En su estudio introductorio Vitar informa que el recorrido por la documentación archivística, los diarios de viajes y, especialmente las crónicas de misioneros como los jesuitas,

(...) es usual toparse con discursos indígenas, en forma de respuestas a los requerimientos de representantes del poder civil o militar, en los prolegómenos de los pactos o en diálogos sostenidos con los misioneros en el transcurso de la cotidianidad reduccional, en medio de los avatares de la asimilación a la 'vida racional' o del proceso de conversión".

19 También pueden encontrarse diálogos entre indígenas de un mismo o de diferentes grupos, como se constata en el texto de Lozano. Vitar se pregunta si estos "testimonios atrapados en la narrativa de la conquista militar y 'espiritual', ¿podrían ser considerados como la versión más aproximada de lo que constituiría una fuente indígena 'indirecta'?”. Vitar opta por definir a las crónicas como monólogos dialogantes, "en los que, por lo general, los argumentos del orden hegemónico aparecen como expresión de legitimidad o criterios de autoridad, en oposición a los razonamientos o concepciones nativas". alcances de los textos de los misioneros del Brasil para conocer la realidad indígena: 
¿Cómo hacer una antropología y una historia de las poblaciones autóctonas a partir de las fuentes misioneras? ¿En qué medida los misioneros comprendieron realmente las culturas indígenas? ¿En qué tipo de textos misioneros encontramos información etnográfica (en los tratados de descripción de costumbres, en las cartas)? ¿Podemos hablar de saberes misioneros sobre los indios? (Castelnau, 2011, p. 270, traducción propia).

Durante el siglo XX, tanto la historia de la iglesia como la antropología americanista, consideraron los textos de los misioneros como descripciones objetivas tanto de la concepción misionera de la evangelización como de la realidad indígena. Los antropólogos americanistas tendieron a reificar las informaciones incluidas en las cartas como descripciones objetivas de creencias, o evidencias claras de una religión coherente ${ }^{5}$. Tales visiones fueron posteriormente criticadas siguiendo la suposición de que el saber misionero no puede ser plenamente reconocido como antropológico, pues los misioneros en realidad no supieron, ni pudieron, ni quisieron entender a los indígenas en sus especificidades y diferencias. Por definición, literatura misional y literatura etnológica serían contradictorias. Castelnau sugiere recuperar la dimensión misionera del texto, lo que implica tener en cuenta la relación de la institución religiosa (la orden) tanto con la producción de información que sirva a la administración, a la edificación espiritual, sin descuidar la curiosidad genuina que algunos textos manifiestan. Según la autora,

(...) las costumbres indígenas descritas por los antiguos cronistas son indisociables de la relación que podía existir entre los indios y quienes los describieron. Las angustias de los misioneros no deben ser ignoradas o separadas como signos de etnocentrismo desplazado, sino analizadas, ya que son reveladoras para el lector contemporáneo (...) Las fuentes misioneras llevan las huellas de la interacción misionera, que deben ser descritas por los especialistas, tanto de los indígenas como de los misioneros". (Castelnau, pp. 276-7, traducción propia)

Quizás debido a las duras condiciones de vida que se imponía a los misioneros en las misiones de frontera, es que su discurso a veces experimentaba sutiles deslices motivadores de reflexiones descentradas sobre su propia biografía y la interacción que mantenían con algunos líderes indígenas. Los textos misioneros (y los misioneros mismos), en el afán por buscar una cierta adaptación, se exponían a la posibilidad y el riesgo, extremos, de indianizarse (Wilde, 2011, 2012; Giudicelli, Havard y Bernabeu, 2012; Del Valle 2009) ${ }^{6}$.

\section{Una era de transiciones: en los albores de las independencias}

La quinta contribución al dossier pertenece a Francismar Alex Lopes de Carvalho, quien presenta documentos de la región chiquitana de la época posterior a la expulsión de los jesuitas (1767). A diferencia de lo que ocurrió en otros espacios de misión, en Chiquitos los sacerdotes continuaron como gestores de los asuntos económicos de los pueblos de reducción hasta la última década del siglo XVIII, cuando fueron sustituidos por los administradores laicos. El período se caracteriza por la aplicación de una serie de reformas encaradas por la administración colonial, las cuales estuvieron precedidas por la redacción de informes sobre el estado de los pueblos. Por entonces estos se encontraban en una profunda decadencia y las reformas se orientaban a fomentar las actividades productivas (fundamentalmente la agricultura y la industria, pero también el comercio), con el objetivo de que recuperasen su antiguo esplendor. Resulta de interés el fomento a 
actividades como la industria textil, sobre la que insisten los informes. Incluso uno de ellos adjunta una muestra (ver fotografía que acompaña la fuente de Carvalho) con varios tipos de tejidos. Sobre ellos aclara el funcionario:

Dirijo a V.E. por Quatriplicado treinta y seis muestras de los texidos mas finos que están texiendose en Oficinas de estos Pueblos en este año, y de los Rosarios, q.' se hacen también p.r los Naturales, cuyos establecimientos e dirijido. (...) en los anteriores Goviernos no a habido estas Labores, sino las de lienzos ordinarios, y Rosarios toscos, habiendo logrado al mismo tiempo aumentar, y mejorar el Veneficio de la Zera que producen estos Montes, a favor de la temporalidad de los pueblos, y en Veneficio de estos Naturales y su fomento. guaraníes producidos entre 1768 y 1831 en las misiones del Paraguay, los cuales remiten a una transición parecida a la que Carvalho estudia en la región vecina. Este amplio período de sesenta años permite identificar modulaciones en el discurso indígena, en un momento clave de transición entre la Colonia y las independencias. Los autores transcriben una serie de documentos ordenados y contextualizados en una cronología conformada por seis eslabones: 1) la expulsión de los jesuitas, 2) la crisis postjesuítica, 3) la época de reformas, 4) la era de la revolución, 5) el ciclo artiguista, 6) la disolución de los pueblos y el éxodo de la población. Los documentos, en su mayor parte en guaraní, permiten identificar contextos particulares de interacción entre los líderes indígenas de las misiones jesuíticas del Paraguay y las autoridades coloniales y republicanas. Salvo en un caso, la conocida proclama bilingüe de Belgrano a los pueblos de misiones, todos los documentos fueron escritos de puño y letra por los indígenas, lo que demuestra su plena autonomía en el manejo de una tecnología clave en la administración colonial y republicana. a partir de documentación correspondiente al período jesuítico, la contribución de Couchonnal y Wilde permite seguir el rastro de la escritura indígena hasta bien avanzado el siglo XIX, identificando algunos rasgos de transformación que aún deben ser estudiados desde una perspectiva multidisciplinaria. Los autores proponen una serie de hipótesis 
orientadas a pensar las modificaciones en el vocabulario político, el proceso de secularización e individuación, el fenómeno de la hispanización y la "reoralización" y las variaciones sincrónicas de los usos de la lengua.

El abordaje de las "fuentes indígenas" de este período resulta de importancia fundamental para la comprensión de las nuevas formas de protagonismo político subalterno en los procesos revolucionarios, tema que ha sido poco estudiado hasta el momento por la historia y la antropología. La autonomía que muchos de estos actores habían ganado durante la época colonial a partir del control de sus organismos locales de poder (concretamente los cabildos) contribuyó a que definieran posiciones desde el momento de la caída de la monarquía ibérica, colocando en el centro disputas por la "soberanía" y la "representación". El período resulta clave también por la progresiva desaparición de los indígenas como tales en las fuentes. Las reformas encaradas en el período colonial tardío, orientadas a homogeneizar culturalmente a la población rural y a asimilarla a un mismo patrón de civilidad, se profundizaron en la etapa independiente. Entonces, los indígenas devinieron "ciudadanos", invisibilizando sus antiguas marcas diferenciadoras, aunque ciertamente persistió su posición subordinada en la nueva sociedad.

\section{BIBLIOGRAFÍA}

Bernabeu, S., Havard, G. y Giudicelli, C. (Eds.). (2012). La indianización. Cautivos, renegados, "hombres libres" y misioneros en los confines americanos (siglos XVI a XIX). Sevilla: CSIC/EEHA/EHESEditorial S-Doce Calles.

Boccara, G. (2012). ¿Qué es lo "etno" en etnohistoria? La vocación crítica de los estudios etnohistóricos y los nuevos objetivos de lucha. Memoria Americana, 20 (1), 37-52.

Bouysse-Cassagne, T. (1997). De Empédocles a Tunupa: evangelización, hagiografía y mitos. En T. Bouysse-Cassagne (Comp.). Saberes y memorias en los Andes. In Memoriam Thierry Sagines (pp. 157-212). Lima: CREDAL-IFEA.

Castelnau, C. (2011). De l'observation à la conversation: le savoir sur les indiens du Brésil dans 1 'ouvre d'Yves D'Évreux. En C.d. Castelnau-L'Estoile, M.L. Copete, A. Maldavsky y I.G. Zupanov (eds.), Missions d'évangelisation et circulation des savoirs. Madrid: Casa de Velazquez.

Cerno, L. y Obermeier, F. (2013). Cartas de indígenas potiguaras de las Guerras Holandesas en el Brasil (1645-1646). Corpus - Archivos virtuales de la alteridad americana, 3 (1). Disponible en http:// corpusarchivos.revues.org/368

Combès, I. (2010). Diccionario étnico. Santa Cruz la Vieja y su entorno en el siglo XVI. Cochabamba: Itinerarios/Instituto de Misionología.

Gell, A. (1998). Art and agency: An anthropological theory. Oxford - New York: Clarendon Press.

Herzog, T. (2007). Terres et déserts, société et sauvagerie. De la communauté en Amérique et en Castille a l'époquemoderne. Annales HSS, 3, 507-538. 
Metraux, A. (1928). La religion des tupinamba et ses rapports avec celle des autres tribus tupi-guarani. Paris: Libraririe Ernest Leroux. Bibliothèque de L'École des Hautes Études en Sciences Religieuses.

Noelli, F. (1999). Curt Nimuendajú e Alfred Métraux: a invenção da busca da "terra sem mal". Suplemento Antropológico, 34 (2), 123-166.

Pompa, C. (2004). O Profetismo Tupi-guarani: a construção de um objeto antropológico. Revista de Indias, LXIV(230), 141-174.

Stern, S. (1992). Paradigmas de la Conquista: historia, historiografía y política. Boletín del Instituto de Historia Argentina y Americana "Dr. Emilio Ravignani", 6, 7-40.

Susnik, B.(1965). El indio colonial del Paraguay I: El guaraní colonial. Asunción: MEAB.

Valle, I. del (2009). Escribiendo desde los márgenes. Colonialismo y jesuitas en el siglo XVIII. México: Siglo XXI Editores.

Wilde, G. (2009). Religión y poder en las misiones de guaraníes. Buenos Aires: Editorial SB.

Wilde, G. (Ed.). (2011). Saberes de la conversión. Jesuitas, indígenas e imperios coloniales en las fronteras de la cristiandad. Buenos Aires: Editorial SB.

Wilde, G. (2012). Indios misionados y misioneros indianizados en las Tierras Bajas de América del sur. Sobre los límites de la adaptación cultural. En S. Bernabeu, C. Giudicelli, y G. Havard (eds.), La indianización. Cautivos, renegados, "hombres libres" y misioneros en los confines americanos (siglos XVI a XIX)(pp. 291-310). Sevilla: CSIC/EEHA/EHESS-Editorial Doce Calles.

\section{NOTAS}

1. Para un contraste de interés con las estrategias españolas remitimos a las cartas publicadas por Cerno y Obermeier (2013) en la primera parte de este dossier, referentes al Brasil holandés.

2. Esta es una característica de las crónicas tempranas del Río de la Plata ya presente en descripciones como la conocida crónica de Ulrico Schmidel, quien identifica innumerables etnónimos que hasta hace poco tiempo no habían sido sistematizados. El intento más reciente en este sentido es el Diccionario étnico publicado por Isabelle Combes (2010). Para la región del Paraguay temprano, los estudios más significativos siguen siendo de Branislava Susnik (1965).

3. Sobre la cristianización de mitos indígenas y la indianización de mitos cristianos ver el artículo de Thérèse Bouysse Cassagne (1997) sobre Tunupa, figura asociada al apóstol Santo Tomás en los relatos misioneros.

4. Resulta sugestivo pensar a las fuentes indígenas, siguiendo a Alfred Gell, como un "índice" de una agencia (una materialidad), capaz de remitirnos, por medio de una concatenación de eslabones, a un primer agente (o "artista") "indígena" (Gell, 1998). El mismo esquema de Gell podría aplicarse para pensar en otras situaciones, en las que el agente primario no es necesariamente "indígena" sino que se encuentra diseminado en la cadena de mediaciones.

5. Métraux, por ejemplo, considera directamente a los misioneros como antropólogos. Su reconstrucción de la religión tupinambá está enteramente basada en los relatos de los misioneros (Métraux, 1928). Por su parte, nota Castelnau en el texto ya citado, en su edición crítica de la obra de Yves D’Evreux, Hélène Clastres incluye solamente la información que considera de interés antropológico sobre las cosmologías nativas y omite la parte dedicada a la edificación espiritual y la ingeniería social desenvuelta por los misioneros, asumiendo que esta de alguna manera contamina la información etnográfica "pura", de otras secciones de esos escritos. Para una crítica de la reificación de ciertos aspectos de la religión guaraní, como la "Tierra sin mal”, ver Pompa (2004) y Noelli (1999). 
6. Puede decirse que la escritura del exilio jesuítico plantea un cambio cualitativo de orientación. Se hace más "científica", en tono con el espíritu de la época, ligado a la necesidad de producir un conocimiento distante, analítico, hasta cierto punto desapasionado, basado en la recolección de datos y la observación empírica. Jesuitas como José Jolis, Joaquín Camaño o José Sánchez Labrador, entre otros misioneros del Paraguay exiliados en los Estados Pontificios después de 1768, se guían por esos principios. Todos ellos produjeron sendas monografías naturalistas y mantuvieron contacto fluido con Lorenzo Hervás y Panduro, importante sistematizador de conocimientos lingüísticos sobre las sociedades indígenas del mundo. Nos hemos detenido en la doble faceta (etnográfica y etnológica) del discurso jesuítico en Wilde (2011).

7. La traducción es del coordinador del debate. Un proceso muy parecido se constata en las reducciones de guaraníes, donde las autoridades coloniales también buscan introducir símbolos de la autoridad real y reformar la administración económica. Sobre el tema ver Wilde, 2009.

\section{AUTOR}

\section{GUILLERMO WILDE}

Instituto de Altos Estudios Sociales - Universidad Nacional de San Martín, Consejo Nacional de Investigaciones Científicas y Técnicas, Argentina

Correo electrónico: guillermowilde@gmail.com 